\title{
A IMPORTÂNCIA DA COMUNICAÇÃO NO PROCESSO LICITATÓRIO NAS INSTITUIÇÕES CONTEMPORÂNEAS
}

\section{ARTIGO ORIGINAL}

JUNIOR, Jorge Luiz Machado ${ }^{1}$

PETINE, Elines Tatianes Pereira Dos Santos ${ }^{2}$

JUNIOR, Jorge Luiz Machado. PETINE, Elines Tatianes Pereira Dos Santos. A importância da comunicação no processo licitatório nas instituições contemporâneas. Revista Científica Multidisciplinar Núcleo do Conhecimento. Ano 05, Ed. 08, Vol. 11, pp. 27-43. Agosto de 2020. ISSN: 2448-0959, Link de acesso: https://www.nucleodoconhecimento.com.br/administracao/instituicoescontemporaneas

\section{RESUMO}

As Instituições Contemporâneas apresentam um complexo contingente de recursos e ações onde às comunicações internas e externas são indispensáveis à sua eficiência operacional. A Licitação, mecanismo de externalização de demandas institucionais, é um dos processos administrativos mais comuns. Considerando a necessidade de divulgação destas demandas, a Comunicação Institucional se torna uma das principais ferramentas aplicadas. Neste contexto, é relevante discutir a configuração contemporânea das instituições com foco em seu processo licitatório e a importância da comunicação para lisura do processo. Este estudo, baseado em uma revisão bibliográfica qualitativa, após se aprofundar nos aspectos conceituais pertinentes, inferiu que a qualidade da comunicação institucional é fundamental não apenas para a proficuidade do processo licitatório, mas também para garantia da probidade

1 Formando Bacharel em Administração Pública (UFF) 8ํㅜ período e Formado em Gestão Pública (UNISUL).

${ }^{2}$ Graduação em Administração Pública. Mestrado em Administração. 
administrativa esperada para um processo em conformidade com os princípios constitucionais.

Palavras-chaves: Comunicação, instituições contemporâneas, licitação.

\section{INTRODUÇÃO}

A Sociedade Civil Contemporânea impôs demandas complexas às instituições. Demandas legais, políticas, sociais e administrativas na produção de seus objetivos. Com o aprofundamento da sociedade capitalista moderna, as instituições passam por mudanças fundamentais onde funções sociais baseadas na manutenção de um feudalismo tardio se eliminam em nome das novas ideias liberais e sua consolidação no capitalismo transnacional. As funções sociais num espectro feudal são desmontadas no processo histórico que estrutura funções como a defesa das liberdades civis e dos valores do estado liberal.

Esta sinergia entre as estruturas sociais e a construção coletiva das instituições contemporâneas se aplica as duas maiores instituições da sociedade moderna, o Estado e o Mercado. Suas características seriam o resultado de um processo de "aprendizado social" que foi ressaltado por Teixeira e Penteado (2016) como um processo dinâmico de transformação resultante de práticas sociais concretas em consonância com a teoria relacional de Pierre Bourdieu, para quem, o Estado (e o mercado) tem "o poder do exercício de uma violência simbólica representada sobre a forma objetiva da estrutura social e ao mesmo tempo com a produção de mecanismos estruturantes".(TEIXEIRA; PENTEADO, 2016)

O mundo contemporâneo também transformou estas instituições modernas, sob novos valores sociais, em busca de eficiência na promoção de objetivos institucionais. Com as crises do meio do século XX e o avanço dos modelos neoliberais de edificação do estado e da sociedade, observa-se um novo e imbricado processo de burocratização articulado com um estado mínimo investidor na iniciativa privada. Tais processos viabilizam transparência no financiamento institucional, assim como acesso a canais de financiamento tanto públicos quanto privados (além das políticas de RC: 58219

Disponível em: https://www.nucleodoconhecimento.com.br/administracao/instituicoescontemporaneas 
crédito). Os setores administrativos e legais tornam-se cada vez mais especializados pelo contingente de conhecimentos envolvidos nas rotinas profissionais ganhando um núcleo central em todas as instituições contemporâneas. Um novo modelo de fazer social articulado como um centro operativo, os setores administrativo e jurídico tornam-se observadores centrais sinergicamente articulados com todas as outras faces da mesma instituição (FLORENZIANO, 2007) (CUNHA, 2010).

A Comunicação Institucional hoje é mais que fundamental e uma utilização eficiente desta, assim como o domínio de suas diferentes formas, é suficiente, em muitos casos, para se obter sucesso nos empreendimentos institucionais. A Licitação é uma destas ferramentas fundamentais. Visando comunicar interesses das instituições tanto na contratação de serviços de forma democrática, quanto na articulação entre sociedade e instituição. Será apresentado o contexto das Licitações em instituições contemporâneas, definir sua importância na sociedade atual e discutir a importância fundamental da comunicação em todo seu processo (KUNSCH, 2018).

\section{METODOLOGIA}

O presente manuscrito é o resultado de uma pesquisa exploratória baseada em uma revisão bibliográfica de abordagem qualitativa. Foram explorados conceitos aferidos tanto em estudos de caso quanto em artigos científicos que tratam do tema. Este conteúdo será cotejado usando as informações levantadas para delimitar com precisão a importância da comunicação no processo licitatório nas Instituições Contemporâneas.

\section{DESENVOLVIMENTO}

As instituições atuais transparecem um rico percurso historiográfico que expressa muito das tendências sociais em cada momento de sua existência. As instituições são nome dado às organizações erigidas pelo fazer humano social. Foram e são elaboradas por acordos humanos e estruturas sociais. Carregam os interesses próprios ou coletivos da humanidade na atenção de interesses privados e públicos. 
Pensadas como uma organização social humana, elas estão presentes em todo percurso social humano. Este artigo abordará a configuração contemporânea de instituições com foco em seu processo licitatório.

As Instituições Contemporâneas são resultado de uma antiga formulação, então não se pode compreendê-las em sua complexidade e integralidade destacando-as de processo social e histórico. Vive-se hoje numa sociedade civil com direitos e deveres sociais observados por todos cidadãos reconhecidos por um Estado Nacional numa sociedade Democrática e de Direitos. As Instituições são livres nesse tipo de sociedade. E isso significa autonomia social e jurídica para agir como deseja dentro de limites sociais controlados por leis e órgãos fiscalizadores observando os processos sociais e aferindo violações dos mesmos. Tal processo não surge do nada, advém da elaboração humana numa relação imbricada entre vontade, articulação política e interesses humanos sob potenciais e limites da tecnologia humana e social para atingir as metas-fim (MARTINS, 2013) (MAGALHÃES, 2017).

Nem sempre foi assim, certamente. Algumas Instituições existem a muitos séculos sentindo em suas entranhas institucionais o peso da mudança e o desgaste das manutenções. Fora todas as outras instituições com percurso de existência mais breve, é importante a definição produzida na modernidade de um carácter social fundamental das mesmas: sua divisão entre públicas e privadas. Ao passo que as monarquias absolutistas perdiam poder efetivo nos impérios feudais, as atividades das burguesias nacionais passam ao centro das Instituições. Os interesses sociais norteadores de suas atividades. De um poder monolítico à nuvem de agentes sociais políticos norteadores das atividades (BENDIX, 1996) (MIGLIOLI, 2010).

Esta perspectiva democrática, onde múltiplos agentes sociais intervêm nos interesses institucionais aplicaram valores e ideais desses novos grupos interventores. Obter eficiência se tornava cada vez mais complexo. Elaborar um conceito do que era eficiente não era mais monolítico. Era necessário organizar o debate, articular semelhanças e intervir no coletivo. As instituições já não são mais as mesmas. A propriedade vem como um direito anterior ao poder e como de arbítrio dos próprios 
indivíduos, não de um terceiro. As Instituições passam a precisar atender ao resultado destas disputas coletivas sobre limites da vontade de outros sobre a propriedade individual (GRAZZIOTIN, 2003).

Importante pontuar que o absolutista medieval sempre dispunha de arbítrio sobre as posses do seu território. Era possível usufruir de todas as riquezas produzidas por seus súditos. Riquezas consideradas próprias do mesmo absolutista. É uma sintetização de um processo de poder de hierarquia vertical acentuada instituída em povos em todo globo por centenas de anos. Os sistemas de pensamento necessários para sua consistência social foram variados, porém compartilhavam crenças que valorizavam subserviências sociais aos poderes monolíticos (principalmente em estruturas culturais teístas). Mas, uma outra figura social despontou com os acúmulos de riquezas, a burguesia europeia com grande influência social obtida pelo acúmulo de riquezas e hereditariedade. Novas tecnologias sociais que permitiu a Europa sair de uma dura gestão de parcos insumos agrícolas e sociais para administração de sobras. Se há sobras, então, as inversões econômicas permitem enriquecimento e ampliação populacional e fortalecimento de comércios. Os súditos envolvidos com comércio passaram a enriquecer em gerações de hereditariedade e certa estabilidade social. Garantiam a riqueza absolutista ao passo que construíam as próprias. Muita riqueza, nenhum poder e a equação se faz completa. Pressionados, absolutistas caem por todo globo em nome dos interesses de uma coletividade burguesa que seria ineficiente sem a capacidade de crenças individuais causarem interferência social (HUBERMAN, 2010).

A relação servil no feudalismo era mantida pela força física de milícias, mas também por um sistema de crenças propagado pelas instituições de fé que associava as relações humanas com a dimensão divina. A religião, assim, possuía expressividade e poder social que foi identificada pela burguesia emergente como legitimadora do absolutismo. A crítica burguesa ao comportamento social denunciava monarcas como hipócritas com relação às crenças religiosas vigentes assim como fazia uma reivindicação da moral do trabalho que legitimava a riqueza pessoal e a livre escolha do que fazer com ela. A propagação de então novas ideias de liberdade de 
organização e orientação social de instituições não poderia ser de apenas um soberano e que as vontades legítimas dos indivíduos eram superiores as ideias de servidão gratuita. Assim, o debate sobre a laicização social tomou proporção política gerando novas relações institucionais. Além disso, as Revoluções Científica, Francesa, Industrial e Gloriosa foram marcos históricos da formulação da Sociedade Civil e foram determinantes na queda dos impérios absolutistas para a edificação dos Estados Nação de Repúblicas e Monarquias Parlamentaristas. Sistemas políticos que organizavam a legitimidade dos regramentos sociais e sua efetiva aplicação e fiscalização nas sociedades pós-feudais modernas (FLORENZANO, 2007) (MIGLIOLI, 2010).

As definições de público e privado passam a ser redefinidos num debate republicano/parlamentarista na edificação das Democracias Contemporâneas. As Instituições, agora sob a égide das liberdades civis não respondem aos antigos tratados burocráticos absolutistas. Respondem aos códigos civis construídos historicamente pela política dos estados-nação. O pensamento filosófico liberal reivindica como um dos princípios fundamentais do indivíduo a sua propriedade privada. Essa compreensão permitiu entender limites da apropriação de estruturas ou três como o estado ou o monarca sob a utilização das propriedades individuais construídas historicamente tanto pelo ser individual quanto por sua herança familiar. O entendimento sobre as limitações e contornos desta propriedade varia ou entre os principais intelectuais do pensamento liberal moderno,mas o princípio da propriedade privada como uma das estruturas arregimentadoras da vida social é bem definida na modernidade e avança sobre novas construções de entendimento nas eras contemporâneas (VACCA, 1991) (BENDIX, 1996) (CUNHA et al, 2010).

Com as primeiras crises do capitalismo na década de 20 do século $X X$, assim como primeira e segunda guerras mundiais, os conflitos entre os sistemas liberais instituídos e seus críticos socialistas, comunistas e anarquistas durante a guerra fria, vê-se a polarização e a disputa entre sistemas econômicos e políticos referenciados em teorias sociais distintas e propostas políticas defendidas por grupos sociais distintos. Assim, o mundo vai de um sistema liberal capitalista republicano para a dicotomia com 
experiências socialistas. Entre eles um mundo de influência onde foi possível perceber diversos modelos referenciados em valores e propostas legais e institucionais de um ambos os modelos: liberal e socialista. Enquanto as instituições liberais primavam pelas teorias tradicionais que entendiam a função do Estado como um legislador natural com organicidade reduzida visando a não interferência de poderes alheios à vontade individual sobre suas próprias fortunas (vale lembrar que este sistemas teóricos e institucionais são formados objetivando reduzir o poder de monarcas absolutistas sobre grupos sociais civis durante a era medieval permitindo o livre mercado burguês), no estado socialista vê-se uma institucionalidade de ampla abrangência dominando todo o setor produtivo e de mercado além de legislar sobre as fortunas e diversos outros aspectos do mercado (MAXIMILIANO, 1995).

A institucionalidade socialista tem particularidades derivadas da articulação teórica produzida por burgueses e pequenos burgueses numa Alemanha industrial republicana onde a expansão das metrópoles convivia com uma enorme massa populacional se dedicada ao trabalho nas fábricas por salários irrisórios com pouquíssimo poder de negociação de sua mão de obra de trabalho. A questão social, ou, a forma como a sociedade se estruturava, se organizava levando em conta aspectos econômicos e culturais assim como históricos e jurídicos, se tornando um dos principais focos de estudo de diversos intelectuais da época. Com uma teoria de focada na natureza do trabalho e sua divisão social, os socialistas desenvolveram a compreensão que parte do processo de produção dos trabalhadores individuais era retirada por um sistema de divisão sócio técnica do trabalho que gerava um elemento nominado alienação (FRANCO, 2011).

Alienação é o processo em que o trabalhador não se vê no produto social do seu trabalho por estar imerso em um sistema de produção típico das sociedades industriais com altíssima especialização do trabalho e complexidade das estruturas laborais e produtivas. Logo, para haver a possibilidade do trabalhador entender-se no produto final de seu trabalho demanda de um processo complexo de dominação dos meios sociais por parte dos operários (trabalhadores) de modo que paulatinamente se tornem coletivos os meios de produção gerando autonomia dos trabalhadores. As 
teorias políticas variam com relação aos processos de transformação social, porém concordam basicamente em períodos intermediários de tomada política e conflito de interesses. As revoluções socialistas tomaram principalmente os primeiros cinquenta anos do século 20. Formaram grandes potências políticas, econômicas e culturais em todo globo. Sua burocracia criava canais de controle social e intervenção estatal em empresas privadas assim como uma forte rede de controle social (MAXIMILIANO, 1995) (FRANCO, 2011) (ALVES, 2013).

As instituições contemporâneas são fruto de um processo histórico que reflete a tensão entre dois grandes blocos de pensamento internacional e suas influências nos países periféricos a esse debate. Os conceitos de público e privado então tem abordagens completamente distintas dependendo desse ponto referencial possível. Funções das instituições públicas e privadas são pensadas de forma diferentes segundo estes modelos. A maior parte do planeta segue modelos de estrutura institucional liberal, porém o modelo socialista advindo das influências da guerra fria também configura uma parte significativa dos modelos institucionais republicanos contemporâneos. Políticas de bem-estar social que conferem ao Estado uma função promotora de direitos e garantidora de sistemas democráticos resenha limites estatais e funções sociais de empresas e instituições privadas. A influência de interesses populares provocou tensões e restrição de limites do poder privado tornando a relação entre as instituições privadas e as sociedades contemporâneas mais complexas devido ao número maior de interações e impactos que levaram a reflexão sobre os limites e papéis distribuídos entre a lógica de público e privado (MAXIMILIANO, 1995) (VACCA, 1991) (CUNHA et al, 2010) (TEIXEIRA; PENTEADO, 2016).

A instituição contemporânea atende as demandas sociais de uma comunidade humana interativa, informada, articulada e organizada por códigos civis e leis que definem possibilidades e limites em sua atuação pública e privada. Isso significa que as instituições hoje possuem limites definidos socialmente sobre aquilo que é devidamente próprio dos indivíduos, ao qual nada na coletividade pode interferir, e aquilo que é completamente, ou parcialmente, relacionado com a prática social gerando impacto coletivo nos indivíduos e precisando ser pensado, legislado e 
organizado por uma estrutura coletiva superior hierarquicamente, com poderes coletivos atribuídos para interagir e legislar, aferindo responsabilidades sobre quaisquer abusos ou violações das regras previamente estabelecidas por esta mesma coletividade ou por seus antecessores. As instituições contemporâneas são mecanismos de ordem social que estruturam as regulações jurídicas instituídas pelos códigos jurídicos (como as constituições). Também regulam os comportamentos de um conjunto de indivíduos que tem uma função social, então funcionam através de regras que são mediadas pelas estruturas tanto administrativas quanto jurídicas e sociais (THÉRET, 2003) (MAGALHÃES, 2017).

Essa natureza mediadora das instituições contemporâneas é produto do conflito de interesses numa sociedade, composta por diferentes agentes sociais provenientes de diversas origens. Possuem rotinas que são responsáveis por aplicar as regras de mediação e produzir a intervenção desejada na sociedade na qual está inserida. Assim, a humanidade se organiza através de um número instituições e este conjunto de instituições que se denomina sociedade. Elas são responsáveis pela perpetuação de costumes e valores assim como pela invenção e transformação das normas socialmente impostas. É como se chama as diferentes estruturas sociais durante o passar do tempo com diversos nomes em diferentes culturas. Hoje pode-se referir as instituições tanto como elementos provenientes da sociedade livre civil, uma manifestação da construção republicana pelos pensamentos dos liberais modernos, quanto como organizações sociais estruturadas pelos códigos jurídicos constitucionais de uma nação. Um exemplo desta segunda definição de instituição, pode-se dizer: as universidades, as empresas, os órgãos públicos, fundações, associações, e demais organizações estruturadas em lei. Ambas organizam e estruturam permanências na sociedade contemporânea. Se por um lado se reconhece o peso dos valores e escolhas éticas e morais da sociedade vigente, por outra entende-se a necessidade de positivação teórica e subjetiva de valores através de organizações físicas estruturadas de maneira palpável através de códigos e rotinas sociais materiais e administrativas. Tais instituições informais e formais contemporâneas se complementam na criação de resultados sociais esperados (tanto 
econômicos quanto pessoais e subjetivos). Uma instituição formal, por exemplo, não pode ignorar tabus e valores, assim como escolhas sociais democráticas, para conseguir alcançar seus objetivos. Assim, as instituições estariam conectadas com os cernes culturais e sociais de determinada tradição ou país elemento endógeno que se expressa em rotinas e estruturas construídas pelos homens. O material interno que produz a legitimidade de praticante e apaziguam conflitos sociais de interesses (REIS, 2000) (THÉRET, 2003) (TEIXEIRA; PENTEADO, 2016).

Uma característica comum das instituições contemporâneas é a sua multifuncionalidade. Atendem a diversas necessidades sociais e humanas. Um exemplo é a instituição familiar que tem uma fundamental função econômica na base de consumo assim como funções educacionais na transmissão de valores e garantia de reprodução de conceitos aos novos membros do conjunto humano. O mesmo ocorre com instituições de ensino, que por muitas vezes extrapolam sua função educativa e a tendência cidade sociais, culturais, de saúde e lazer. Ou instituições religiosas que não apenas atendem às demandas metafísicas e subjetivas da sociedade, como também fornecem material político, atendem necessidades sociais e muitas vezes proporcionar alternativas de saúde. Ainda existem as instituições políticas (como partidos políticos e associações livres), instituições governamentais (como prefeituras e ministérios), instituições empresariais (empresas, indústrias, holdings, etc), instituições econômicas (como bancos e investidoras), instituições de lazer (como, festas populares, parques, etc) (TEIXEIRA; PENTEADO, 2016).

Numa sociedade dinâmica livre como as democracias diretas e indiretas contemporâneas, com a invenção da internet e todo o potencial global de comunicação imediata criando um novo patamar para características sociais como transparência, dinamismo, eficiência e conectividade, a comunicação institucional está frente a seus novos desafios. São muitas pessoas, muitos indivíduos, muitos agentes sociais autônomos com diferentes interesses e rotinas onde uma mesma instituição pode perpassar interesses de pessoas de posições sociais completamente opostas. Segundo Lima e Melo (2017), criar um meio de comunicar e atender com eficácia as demandas de troca entre indivíduos e instituições cria ferramentas e 
disciplinas que colaboram na conjugação das rotinas sociais presentes. (LIMA e MELO, 2017)

A comunicação institucional ganha ares de revolucionários na contemporaneidade. Se a modernidade ainda administrava os resíduos de instituições medievais que operavam em cima da ordem dos mistérios privados de poucos nobres e absolutistas, a contemporaneidade alastra o peso do indivíduo e planifica as relações nunca antes vistas na história. As novas demandas culturais contemporâneas exploram valores da transparência e da democracia. É do interesse da maioria dos indivíduos o maior acesso possível a verdade institucional de determinada construção. Se hoje é verdade a privacidade todos os processos individuais, todo público pertence a todos, sendo cabível a todos o direito ao conhecimento sobre determinada rotina institucional. Logo, todo processo coletivo pertence ao conjunto dos cidadãos reconhecidos por uma nação (BENDIX, 1996) (KUNSCH, 2018).

Comunicar valores e objetivos de uma instituição, como uma empresa por exemplo, envolve uma série de ações estratégicas e coordenadas para projetar uma imagem institucional consistente. Como a diversidade tanto interna dos agentes realizadores de determinada instituição, quanto externa, dos atores sociais a quem se deseja alcançar ou indiretamente envolvidos, a comunicação institucional envolve a transmissão endógena e exógenas da comunicação expressão da imagem institucional. Então, a comunicação institucional ou organizacional, tem na contemporaneidade esse esforço deliberado de estabelecer relações de confiança entre os membros da instituição e todo o público envolvido em sua ação cotidiana. Tem função mobilizadora para fomentar a um conjunto de pessoas a concretização de objetivos. Assim, para Angeloni (2010), "a comunicação institucional é uma fomentadora de relacionamentos abrangente, pois se direciona a diferentes públicos na sociedade atual" (ANGELONI, 2010) (KUNSCH, 2018) (NEIVA, 2018).

Comunicação institucional pode ser vista como uma estratégia administrativa, uma técnica de gestão, ou seja, modelo aplicável a qualquer instituição. Da organização da quermesse à multinacional, todos precisam de comunicação institucional. Sem 
comunicação institucional não há possibilidade de obtenção de sucesso na realização dos objetivos institucionais. Colabora para o funcionamento organizacional adequado, gera a sensação de motivação dos agentes internos e externos além da promoção de satisfação pela boa relação desenvolvida. Ela também promove a imagem institucional e gera notoriedade e reconhecimento. Quando bem desenvolvida permite relações fortuitas e duradouras que geram a confiança das instituições contemporâneas com os vários públicos com os quais se relacionam. Não é fácil de ser desenvolvida, mas só pode ser entendida como parte da cultura institucional, não sendo possível ser desagregada das rotinas sociais contemporâneas (SALLES, 2016).

Assim como todo tipo de comunicação, a institucional envolve aspectos técnicos e subjetivos. O que é importante de ser salientado porque é profícuo na literatura de a presença do caráter intencional da comunicação institucional. É preciso motivo para continuar e permanecer, é preciso motivo social para haver uma instituição. Como esse elemento subjetivo vivo, a comunicação institucional está no campo de constante mutabilidade. Demanda persistente adaptação e readaptação para atender as demandas da realidade. Torna fundamental a liberdade de informação e o seu ciclo de circulação cada vez mais aberta e acessível já que tem como objetivo ser assimilado e compreendida pelo máximo de agentes em interlocução (KUNSCH, 2018).

Segundo Tavares (2010), determinada instituição tem: clientes externos, o que são pessoas interlocutoras e organizações, até outras instituições, que são algo possível das ações institucionais propostas tanto de forma consciente quanto inconscientemente. Porém, ainda não contrataram a instituição referida.Clientes internos, como podem ser classificados os trabalhadores de determinada instituição. Os responsáveis por sua manutenção, reprodução e transformação de rotinas.

Com isto em mente, retornando aos objetos formais da comunicação institucional, é recorrente nas rotinas administrativas de estudo e pesquisa apresentação das ferramentas administrativas de comunicação interna e externa. Entre elas o ofício, a 
carta, o memorando, etc. Porém, existem demandas mais complexas que aquelas geradas pelos interesses unilaterais da vontade institucional. As sociedades contemporâneas são um reconhecido o palco das disputas republicanas e democráticas. Isso significa que lida com agentes mediadores e estes agentes são os códigos legais e as instituições regulamentadoras. Alguns processos comuns na sociedade capitalista são baseados em ideias polêmicas sobre os limites da regulação institucional. Alguns processos de compra e venda são passíveis da intervenção de instituições regulamentadoras, assim como reguladas por lei.

Várias ações de instituições contemporâneas são legisladas e muitas são pautadas pela burocracia jurídica para atenção das demandas institucionais brasileiras. Assim como as instituições privadas são regulamentadas, instituições públicas também são. Compreende-se que as instituições públicas têm um papel múltiplo em praticamente todo seu corpo institucional. Por atender a demandas de grupos sociais inferindo na produção de leis e regulamentos institucionais, as instituições públicas estão sob a égide do controle social (CUNHA et al, 2010).

O leilão pertence a dinâmica do mercado desde tempos imemoriais. Nas repúblicas democráticas as instituições respeito as constituições nacionais. Nestas constituições é que podemos ver os regimentos reguladores das licitações privadas e públicas.

Licitação é um termo jurídico. Apesar de aferir sobre bens privados em alguns momentos específicos, como por exemplo numa partilha de herança que envolve a venda de bens coletivos. Porém, seu maior arcabouço jurídico contempla as instituições públicas. Cabe às instituições públicas o respeito integral aos princípios constitucionais que regulamentam a administração pública. Entre eles estão transparência e democracia. Tendo em vista tais princípios, todas as negociações referentes a contratação de bens e serviços assim como venda de bens e serviços devem ser publicizados para toda a população reconhecida por determinada nação (OLIVEIRA; SANTOS, 2014). 
Para Di Pietro (2006), Licitações são um dos processos no espectro da administração pública responsáveis pela análise das melhores propostas de aquisição de um produto ou transação de um serviço. Os processos licitatórios determinam quem será escolhido para efetuar os contratos de fornecimento de produtos e serviços que a administração pública precisa. $O$ processo nitidamente visa fazer a escolha mais vantajosa para as instituições públicas tanto em termos de qualidade como de preço. O processo que oportuniza a apresentação de propostas deve ser estendido ao máximo de pessoas possíveis, sempre oportunizando uma massiva participação de todos os envolvidos em determinado mercado produtivo. Evidentemente que lidar com recursos públicos no cenário tão ávido por informação transparente e legitimidade da utilização dos bens coletivos, é mister apresentar consistente corroboração jurídica que frequentemente se apresenta como expressiva demanda burocrática, tanto para instituições públicas quanto para as instituições e pessoas visando parceria com a mesma. Para tanto, todo processo licitatório demanda comprovação documental apresentando com nitidez jurídica quais são os interesses da vontade institucional proposta em negociação pública (PIETRO, 2006) (CASTRO, 2015).

Neste contexto, a comunicação institucional é fundamental ao processo licitatório. Visto que o mesmo tem como intenção comunicar ao máximo de pessoas e instituições relacionadas aos interesses institucionais propostos, é papel da comunicação institucional realizar os interesses do processo licitatório. Assim ambos se fundem numa mesma intenção institucional. A comunicação institucional dialoga, enquanto o processo licitatório democratiza de forma transparente os interesses de negócio das instituições públicas. Uma estratégia de comunicação institucional bem efetuada garante mais que a adesão aos valores constitucionais presentes. É a estratégia de comunicação institucional adequada que permite a devida efetividade na utilização dos recursos públicos existentes. Devido a uma comunicação institucional eficiente surge uma profusão de instituições e pessoas dentro do espectro de negócio relacionado, o que permite tanto uma escolha mais adequada aos interesses específicos que atendem as vontades institucionais, quanto uma boa 
concorrência que viabiliza economicamente uma série de serviços e produtos no mercado concorrencial (ANGELONI, 2010) (REIS; CABRAL, 2018).

Como as licitações precisam ser abertas a qualquer pessoa, empresa, ou demais instituições relacionadas aos interesses do contratante, também atende a princípios constitucionais de isonomia o que é igualdade de acesso ao mercado e a bens e serviços. É uma ferramenta que busca restringir quaisquer tendências aos favoritismos não-meritocráticos, ou a vínculos de coleguismo em detrimento de qualidade e eficácia. Além de evitar crimes de corrupção e mau uso do dinheiro público. Dentre os mecanismos de licitatórios, também deve haver acessibilidade a todos aqueles dentro do espectro de concorrência ao processo licitatório. É o princípio de publicidade que favorece a participação e o ingresso democrático no mercado propiciando a ampla concorrência geral, de forma sempre igualitária. O processo licitatório também deve ter todos os seus critérios e decisões bem detalhadas, previamente estabelecidas de forma acessível e com prazo hábil para que o máximo de pessoas a quem se interessa atingir possa atender seus requisitos. $O$ edital é o documento comumente utilizado para expressar essas intenções institucionais definindo pontualmente todos os aspectos do processo licitatório: das vontades institucionais ao público-alvo, sem deixar de pontuar todos os limites e regramentos dispostos constitucionalmente de forma prévia com clareza. Os processos de edital permitem a realização do princípio da impessoalidade, já que evitam quaisquer interpretações equivocadas sobre as vontades institucionais previamente estabelecidas. Precisa estar comprometido com as regras da administração de origem ética e moral, assim como entender e aplicar a legalidade vigente seguindo assim o princípio da moralidade. A economia também faz parte dos princípios da administração pública, por isso a opção do processo licitatório no final deve ser pela mais vantajosa para o órgão público referente, envolvendo a melhor qualidade possível pelo menor preço administração. Ainda existem as necessidades de se expressar diretamente qual instituição indaga através de processo licitatório a vontade institucional previamente estabelecida, este é o princípio da vinculação ao instrumento convocatório. É importante também salientar que todo processo que julga deve 
envolver clareza nos critérios com relação ao processo tendo banca cientificamente estruturada dentre as demandas da legalidade que possam aferir sobre determinado posicionamento. O princípio do julgamento objetivo é o que norteia esse processo de aferimento que busca a materialidade das respostas finais de seu julgamento. Considerando a dimensão temporal, o princípio da celeridade visa aplicar os recursos para determinado serviço ou bem com a maior qualidade menor preço e em menor tempo possível que propicia optar sempre pelo caminho jurídico e administrativo mais rápido sem esquecer da qualidade (MUHR, 1986) (BACHTOLD; 2010) (BITTENCOURT, 2015) (AMORIM, 2018).

As leis e regulamentos que estruturam as licitações públicas são fruto do amplo debate nas democracias contemporâneas sobre os limites de atuação do Estado e a forma mais adequada que o mesmo deve se comportar perante o mercado de bens e serviços. É fruto do debate democrático, dentro da sociedade capitalista, do modelo republicano do Estado de bem-estar social inconcluso que coloca uma série de especificidades no caso do Brasil. Tem como função garantir democraticamente acesso a bens e serviços públicos tendo o estado como interventor no mercado de forma isenta. E como visto, esta isenção também está intimamente associada a comunicação institucional.

\section{CONCLUSÃO}

A comunicação tem sido a forma mais eficiente de impacto nas ações político-sociais contemporâneos. Desta forma, tem oportunizado o crescimento de ideias de grupos minoritários antes relegados ao esquecimento e as trocas íntimas de grupos resumidos. Mas a sociedade contemporânea é uma sociedade em redes. Redes, que antes eram profundamente íntimas e reservadas ao espaço de troca dos olhares e limitados a distância do toque, hoje promove trocas públicas em espaços acessíveis a toda comunidade interessada tornando o debate privado em uma discussão pública profunda e acessível. Tais construções sociais na formulação da estrutura de redes fornecem a propagação de ideias com rapidez e movimento. Processos de criação e 
identificação são muito mais rápidos e dinâmicos que o humanamente possível há apenas algumas décadas atrás.

A comunicação é fundamental, o tempo curto e a profusão de informação demanda que um processo institucional seja estratégico e assertivo. Portanto, comunicação institucional de má qualidade pode relegar o processo licitatório ao insucesso, impactando a utilização de recursos e todo processo social. Assim, todas as formas de aprendizado relativa os objetivos institucionais e às técnicas de interação com a sociedade, são tempo bem gasto na formulação das estratégias administrativas de comunicação institucional - parte do processo administrativo que nunca pode ser relegado a segundo plano.

\section{REFERÊNCIAS}

ALVES, G.; Marxismo, a alienação e o tempo histórico da barbárie social do capital; Revista Katálysis, v. 16, n. 1, p. 57-62, jan./jun. 2013.

AMORIM, V.A.J.; Licitações e contratos administrativos: teoria e jurisprudência; Brasília, Ed. Senado Federal. 2017.

ANGELONI, Maria Terezinha. Comunicação nas Organizações da Era do Conhecimento. São Paulo: Editora Atlas, 2010.

BACHTOLD, C. Noções de administração pública. IFPR, 2012. Disponível em: <http://ead.ifap.edu.br/netsys/public/livros/Livros\%20Curso\%20Servi\%C3\%A7os\%20 P\%C3\%BAblicos/M\%C3\%B3dulo\%20I/Capa\%20Nocoes\%20Administracao\%20Publ ica_IFAP/Livro\%20Nocoes\%20Administraca0\%20Publica.pdf>. Acessado em 04/07/2020

BAHIA, Juarez. Introdução à Comunicação Empresarial. Rio de Janeiro, Editora Mauad, 1995. 
BENDIX, R. Construção Nacional e Cidadania: Estudos de nossa ordem social em mudança. São Paulo, Edusp, 1996.

BITTENCOURT, S.;Licitação através do regime diferenciado de contratações públicas - RDC. 2. ed. Belo Horizonte: Fórum, 2015.

CASTRO, A.O. Como Participar de Licitação Pública. [S.I: s.n.], 2015. Disponível em: https://www.sebrae.com.br/Sebrae/Portal Sebrae/Anexos/cartilha_licitação.pdf.

CUNHA, A.S.; MEDEIROS, B.A.; AQUINO, L.M.C. Org.; Livro 9: Fortalecimento do Estado, das Instituições e da Democracia; Volume 1: Estado, Instituições e Democracia: República;Projeto Perspectivas do Desenvolvimento Brasileiro - Série Eixos Estratégicos do Desenvolvimento Brasileiro -IPEA; 2010.

DI PIETRO, Maria Sylvia Zanella. Direito Administrativo. Ed. Jurídico Atlas, 19 Edição, 2006.

FRANCO, T. "Alienação do trabalho: Despertencimento social e desrenraizamento em relação à natureza", Caderno CRH, v. 24, n. SPECIAL ISSUE.1, p. 169-189, 2011. DOI: 10.1590/s0103-49792011000400012. .

FLORENZANO, M.; Sobre as origens e o desenvolvimento do estado moderno no ocidente; Lua Nova, São Paulo, 71: 11-39, 2007

GRAZZIOTIN, HA., AVILA, RI., and HERRLEIN JR. A Economia Política Institucionalista e o desenvolvimento. In: DATHEIN, R., org. Desenvolvimentismo: o conceito, as bases teóricas e as políticas [online]. Porto Alegre: Editora da UFRGS, 2003. Estudos e pesquisas IEPE series, pp. 113-156.

HUBERMAN, L.História da Riqueza do Homem22ª Ed., Editora GEN-LTC, 2010.

KUNSCH, M. M. K. "A comunicação estratégica nas organizações contemporâneas", Media \& Jornalismo, v. 18, n. 33, p. 13-24, 2018. DOI: 10.14195/2183-5462_33_1. . 
LIMA, Sara C. M. G. e MELO, José A. M. A Importância do Endomarketing para a Comunicação Interna. Revista RGI,Out/Nov2017.

MAGALHÃES, C. Instituições de direito público e privado. Salvador, UFBA Superintendência de Educação a Distância, 2017.

MARTINS, C. B. "Em defesa do conceito de sociedade: Resenha", Revista Brasileira de Ciências Sociais, v. 28, n. 82, p. 229-246, 2013. DOI: 10.1590/s010269092013000200014.

MAXIMIANO, A.C. A. Introdução a administração. São Paulo: Atlas, 1995.

MIGLIOLI, J. "Dominação burguesa nas sociedades modernas", Crítica Marxista, v. 22, p. $13-31,2010.2$ Disponível em: https://www.ifch.unicamp.br/criticamarxista/arquivos_biblioteca/artigo205Artigo1.pdf.

MUHR,E.; Os critérios de julgamento das licitações;Revista da Administração Empresarial, 26 (2) 5-11. Abr/Jun 1986.

NEIVA, F.; Comunicação das Organizações: Um olhar sobre a importância da Comunicação Interna;HTTPS://DOI.ORG/10.14195/2183-5462_33_4; 2018.

OLIVEIRA, B.C.S.C.M.; SANTOS, L.M.L.; Compras públicas como política para o desenvolvimento sustentável;Revista de Administração Pública(1):189-206, jan./fev. 2015

REIS, F. W.;Mercado e Utopia: Teoria Política e Sociedade Brasileira. São Paulo, EDUSP, 2000.

REIS, P.R.C.; CABRAL, S.; Para além dos preços contratados: fatores determinantes da celeridade nas entregas de compras públicas eletrônicas;Revista de Administração Pública52(1):107-125, jan./fev. 2018 
SALLES, Mônica. Comunicação Estratégica Eficiente: a capacitação dos gestores da organização na habilidade da comunicação. Disponível em http://www.comunicacaoempresarial.com.br/comunicacaoempresarial/artigos/comuni cacao_interna/artigo2.php. Acessado em 19/6/2020.

TAVARES, M. Comunicação Empresarial e planos de comunicação: integrando teoria e prática. 3ed. São Paulo: Atlas, 2010.

VACCA, G.; Estado e Mercado, Público e Privado; Lua Nova, oㅡㄴ 24, set. 1991.

Enviado: Julho, 2020.

Aprovado: Agosto, 2020. 